\title{
Doutores da ética da alegria
}

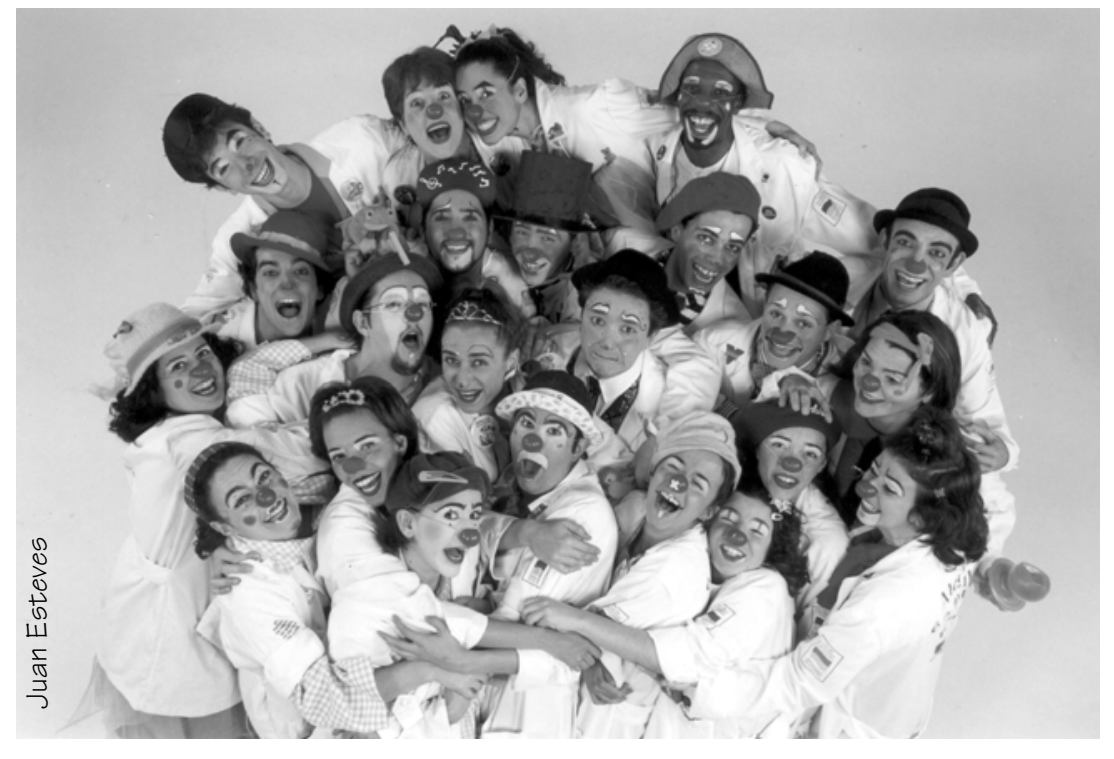

Morgana Masetti ${ }^{1}$

\begin{abstract}
Quem dá conselhos a um homem doente adquire uma sensação de superioridade sobre ele, não importando se eles são acolhidos ou rejeitados. Por isso

há doentes suscetíveis $e$ orgulhosos que odeiam os conselheiros mais que a doença.
\end{abstract}

(Nietzche, 2001, p.198)

Os Doutores da Alegria são uma organização artística do terceiro setor, que desde os anos 1990 leva o trabalho de atores profissionais para dentro de hospitais. Utilizando a figura do palhaço que acredita ser médico e realiza "exames" e "consultas", o artista passa a fazer parte do dia-a-dia das enfermarias, visitando duas vezes por semana todas as unidades em que há crianças e adolescentes internados e interagindo, também, com seus acompanhantes e profissionais do hospital. Em 1991, Dr. Zinho, palhaço pioneiro, possibilitou com essa iniciativa que muitas crianças vissem pela primeira vez um palhaço e uma intervenção teatral. O hospital, então, passou a experimentar fronteiras no mínimo não usuais a sua realidade, reinserindo questões da vida à rotina asséptica e controlada.

\footnotetext{
${ }^{1}$ Psicóloga, coordenadora do Centro de Estudos dos Doutores da Alegria Formação e Desenvolvimento. <morgana.ops @terra.com.br>

${ }^{1}$ Rua Alves Guimarães, 73

Pinheiros - São Paulo, SP

05.410-000
} 


\section{CRIAÇÃO}

Naquela época, a figura do palhaço era algo absolutamente incomum ao cenário das macas e enfermarias. Graciosamente destoante, habilmente desconcertante e não ameaçador. Uma imagem que propunha aos adultos que cruzavam seu caminho um tempo de reflexão para tentar aproximar o mundo médico ao do circo. Isso representava algo novo em uma época em que o pensamento médico evoluía em alguns conceitos. Evoluir? Na ocasião não pensávamos nisso, o programa precisava sobreviver em um contexto ainda dormente para investimento em ações culturais. Entretanto, a semente encontrou um solo propício. Dra. Emily, Dra. Ferrara, Dr. Dog, Dra. Sirena e tantos outros vieram em seguida e vivem com suas inúmeras histórias para contar (hoje são 36 atores, que atuam em dez hospitais, nas cidades de São Paulo, Rio de Janeiro e Recife).

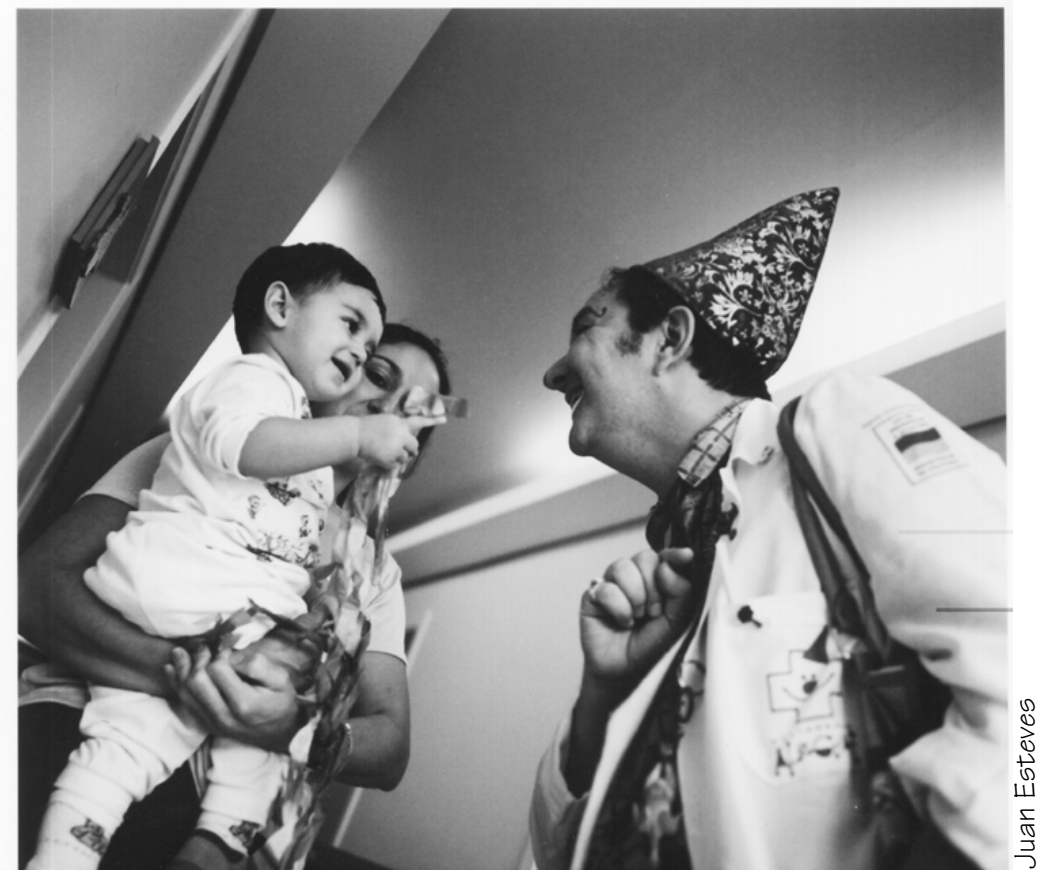


Em treze anos, o terceiro setor cresceu no país. Mais e mais os hospitais passaram a abrir suas portas para atividades "extracurriculares" aos diagnósticos e intervenções técnicas. O tempo passou. Dr. Escrich, Dra. Manela, Dr. Zorinho, Dr. Zapatta Lambada... E mais histórias. Histórias da vida de um povo. Da saúde do país.

Com o que víamos nos hospitais, com os depoimentos dos artistas durante nossas reuniões e os relatórios de atividades escritos por eles, fomos estabelecendo um referencial para a construção de uma ética que valida nosso fazer. Não foi só a decisão de levar o palhaço ao hospital. Agora era também o que o hospital nos contava e sobre o que nos convidava a pensar. A miséria da morte e da vida. A violência do filho espancado, dos órfãos da Aids. Criança com cordão umbilical chegando da lata de lixo. Falta de remédio, falta de sabão, de mãos. E a proposta de continuar a se surpreender com este cenário.

Essas imagens passaram a nos habitar, juntamente com o respeito aos profissionais de saúde cujas carreiras estão repletas delas e, mesmo assim, continuam a investir nas relações humanas. Hoje, treze anos depois, a humanização se instala como a palavra que ordena essas ações: brinquedotecas, bibliotecas circulantes, contadores de histórias, recreacionistas, música, artes plásticas. O número de voluntários cresceu enormemente nos hospitais e a quantidade de grupos que se utilizam da máscara do palhaço também: mais de 180 grupos cadastrados em pesquisa realizada pelo Centro de Estudos Doutores da Alegria em 2001.

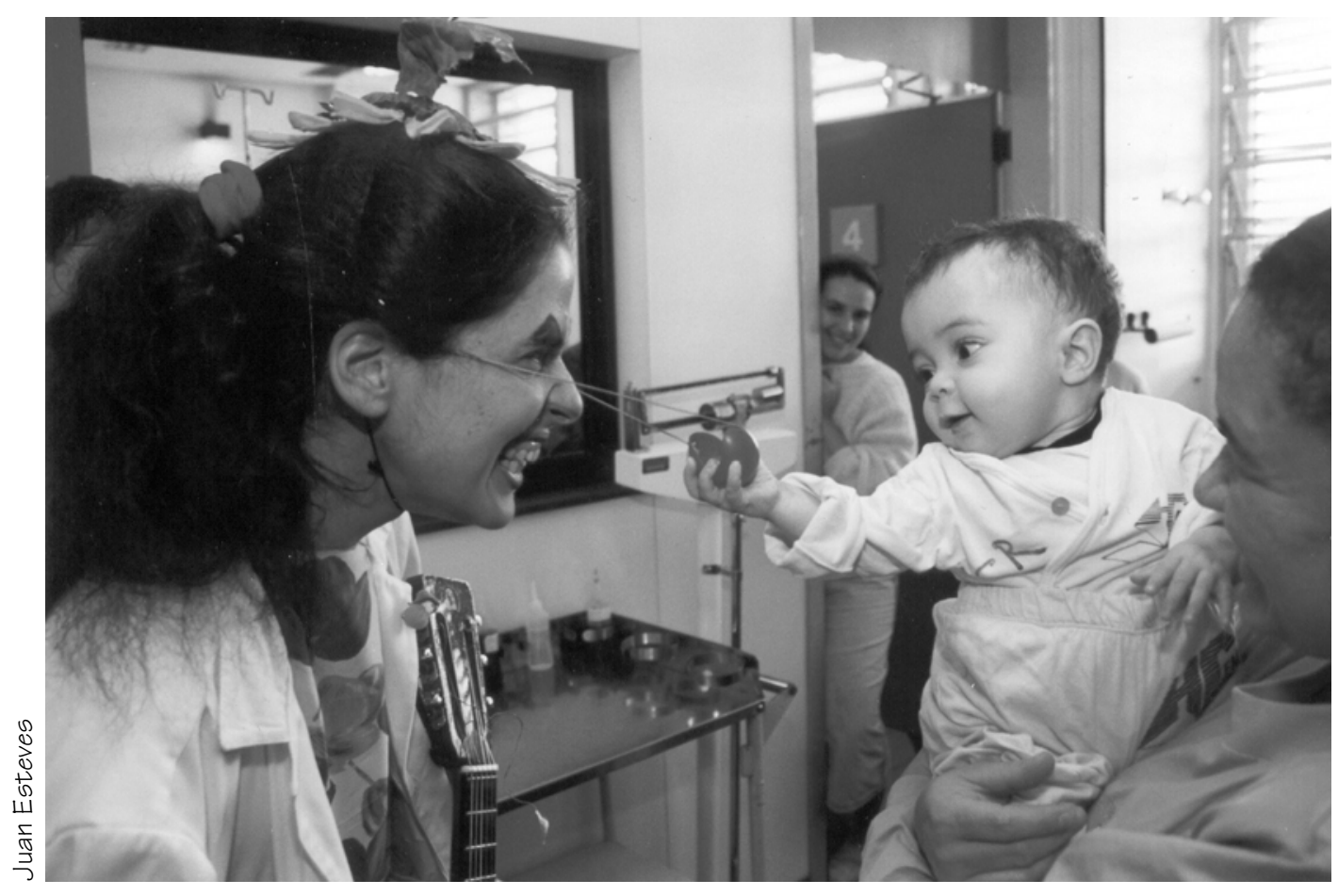




\section{CRIAÇÃO}

Hoje, nossa inquietude é muito maior que no início de nossas atividades. Surgem perguntas diversas: será que todo esse caminhar, aliado ao reconhecimento crescente dos departamentos de humanização, fará com que corramos o risco de ir para casa e dormir tranqüilos, acreditando ter dado conta da complexidade do trabalho a que nos propusemos? Chegaremos a criar uma ISO da humanização para os hospitais? Ou então algo como os "dez passos" para humanizar? Esperamos continuar nas questões essencialmente humanas, para honrar a complexidade do tema.

A atualidade nos traz angústia e oportunidade. A angústia: percebermos que, mais do que nunca, estamos conectados a uma enorme rede. Tudo o que acontece no mundo nos diz respeito, atinge-nos visceralmente. Cada vez mais acordamos para nossa conectividade com outros fusos, com a sociedade planetária da qual fazemos parte. A chamada a essa consciência é palavra de ordem em fóruns sociais, publicações e em nosso trajeto cotidiano. Hoje sabemos que nossa ação individual pode influir, indicar direções, não precisamos mais esperar governos ou instituições e essa lucidez leva-nos para o outro lado da angústia: a oportunidade.

Por que falar disto? Porque qualquer temática social não pode perder de vista essas questões. Elas acarretam conseqüencias à opção de ser um Doutor da Alegria que vão muito além da exigência de um nariz vermelho. Faz com que pensemos na educação do futuro, no mundo em que as crianças de hoje viverão, na oportunidade de criar uma legislação planetária mais justa, menos excludente. Esse cenário contextualiza nossos anseios para encontrarmos a medicina do futuro.

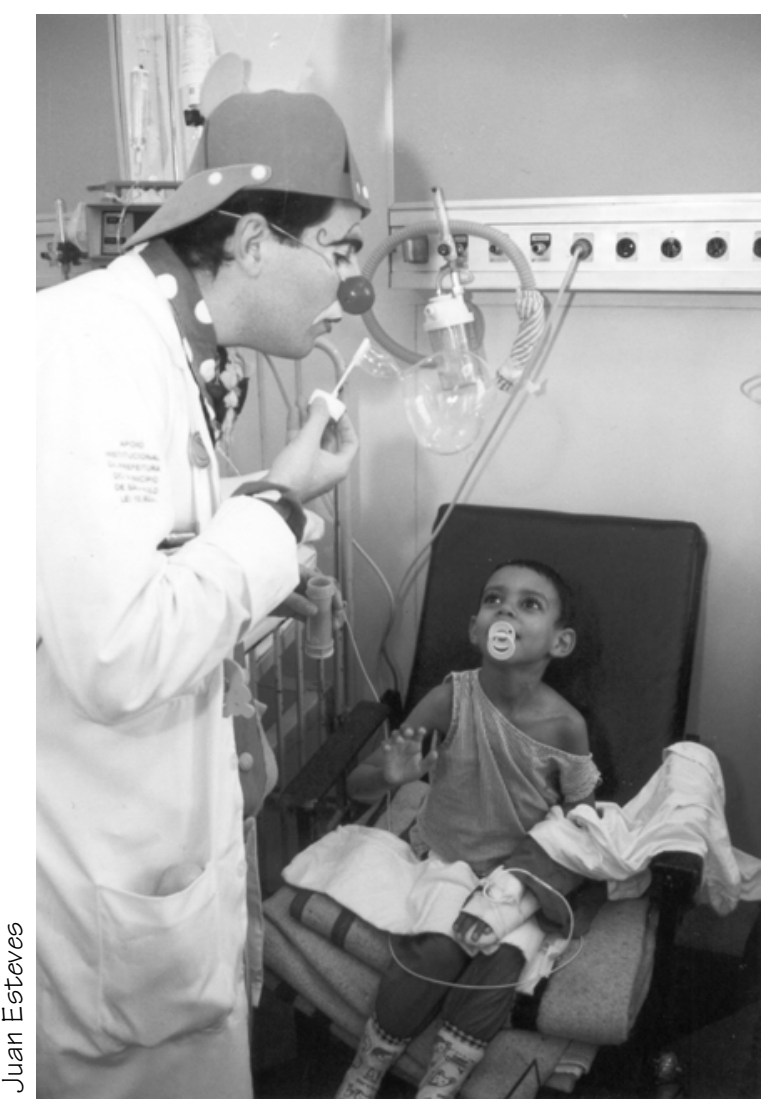

O oficio do palhaço fala do esforço do homem de se entregar à única condição possível de existência: a da relação humana. Ele nos re-conecta com essa potencialidade e com a essência da medicina, esse fascinante universo pelo qual anda nosso imaginário sobre vida e morte, por onde circulam afetos e desejos impressos nos corpos. Espaço em que os sentidos do olhar, ouvir e tocar fazem circular esses acontecimentos.

Por que, então, a necessidade de o palhaço ocupar esse cenário? Talvez porque a medicina, em seu movimento de capitalização, esteja se afastando desse sentir, ameaçando as pessoas à medida que essa riqueza cultural é privatizada e inserida numa lógica econômica. E porque é possível que a atuação do palhaço nos ajude a constatar o absurdo que a apropriação desse imaginário pode significar. 
$\mathrm{O}$ aumento pela procura de terapias alternativas mostra que parte da sociedade está buscando formas de questionar a medicina oficial. Um momento de ambigüidades, em que convivem o modelo médico capitalista americano implantado em hospitais-hotel (ou serão hotéis-hospital?) e os hospitais públicos. Um tempo em que parte do mal-estar da civilização moderna está ligado ao desaparecimento de espaços que incentivem e dêem sentido às forças $e$ questões da vida. Uma época em que a depressão aparece como o segundo problema mundial de saúde, já com projeção para tornar-se o primeiro em dez anos. Uma conjuntura em que o utilitarismo médico fortalece esse mal-estar ao deixar de ser continente para tais questões.

Neste jogo de forças, o cenário das Organizações Não-Governamentais no Brasil está dividido: muitas deixaram de buscar capital para cumprir sua função mobilizadora e tornaram-se uma nova possibilidade de geração de renda dentro da lógica de mercado: bem colocadas no marketing empresarial travestido de responsabilidade social. Peter Pál Pelbart (2000) ajuda-nos a entender um pouco esse movimento. Em seu livro A vertigem por um fio ele nos mostra como o capitalismo, mediante a incorporação de tendências, gestos, modos e opiniões, devora fronteiras e elimina exterioridades, o que Deleuze (1978) chama de "as forças do fora".

Essas forças nos ajudam a colocar o pensamento em estado de exterioridade, quando diversos pontos de vista podem se relacionar. A saúde, por meio da loucura, exemplifica essa possibilidade. A forma como o louco vê o mundo coloca o homem em contato com uma exterioridade enigmática, na qual ele pode se confrontar com outros lados de si mesmo. Com a lógica atual, tanto a loucura como o inconsciente se incorporam ao cotidiano banalizado. A cada dia criam-se novos rótulos médicos para comportamentos bizarros que são descritos $e$, se possível, medicados. Esses comportamentos podem, então, circular no mercado com seu poder de venda e compra de tratamentos, ganhando um espaço de circulação social e perdendo sua exterioridade. Segundo Pelbart (2000), uma grande evidência da incorporação dessa exterioridade ao humano como processo seria o irônico nome de humanização, "através dele e de sua dialética diabólica teremos conseguido o impensável: abocanhar nosso próprio exterior" (p.57).

Sabemos, então, que qualquer tentativa de questionamento atual percorre esses sinuosos e sutis caminhos. A experiência artística construída pelos Doutores da Alegria ajuda a pensar questões da medicina atual, criando exterioridades. Essas linhas de fuga são criadas a partir do modo como o palhaço enxerga a realidade a sua volta. Por meio de sua máscara, esse personagem tem autorização da comunidade para operar sobre uma lógica de pensamento não linear ou racional. O erro, o ridículo, o absurdo são bem vindos como materiais que tornam efetivo esse olhar. Novos pontos de vista são criados: o carrinho das refeições dos hospitais pode se transformar em um trem, devido a seu barulho; $e$ o posto da enfermagem pode virar um balcão de pizzaria. Ou seja, o foco é totalmente concentrado no presente e na construção de uma relação lúdica.

Desta forma, um médico pode assistir a um palhaço interagindo com uma criança inconsciente em uma UTI. Esse fato abre espaço para que algo novo se interponha na lógica cotidiana que diz que ali não existe forma de contato. $\mathrm{O}$ palhaço que trabalha com uma criança poucos momentos antes de ela morrer resgata a força do aqui e do agora, interrompendo a lógica do prognóstico que 


\section{CRIAÇÃO}

define, em geral, o investimento de energia das relações dentro do hospital. A complexidade desses fatores nos levou a criar um Centro de Estudos de pesquisa e desenvolvimento na área. Mediante publicações científicas (ver Masetti, 1998) e Programas de Formação (<www.doutoresdaalegria.org.br>), buscamos criar estados de exterioridade, espaços de potência.

Desejamos colaborar para que a medicina se religue à complexidade social da experiência médica. Como atores desse movimento, estamos inseridos em um enfrentamento entre a lógica da medicina como fenômeno social e a lógica capitalista. Nossa capacidade de criar espaços propícios de reflexão e estabelecer alianças com a sociedade será vital para influir nos acontecimentos futuros.

\section{Referências}

DELEUZE, G. Espinosa e os signos. Portugal: Editora Reis, 1978.

MASETTI, M. Soluções de palhaços: transformações na realidade hospitalar. São Paulo: Palas Athena, 1998.

PELBART, P. P. A vertigem por um fio: políticas de subjetividade contemporânea. São Paulo: Iluminuras, 2000.

NIETZSCHE, F. Humano, demasiadamente humano: um livro para espíritos livres. São Paulo:

Companhia da Letras , 2001.

$<$ http://www.doutoresdaalegria.org.br>

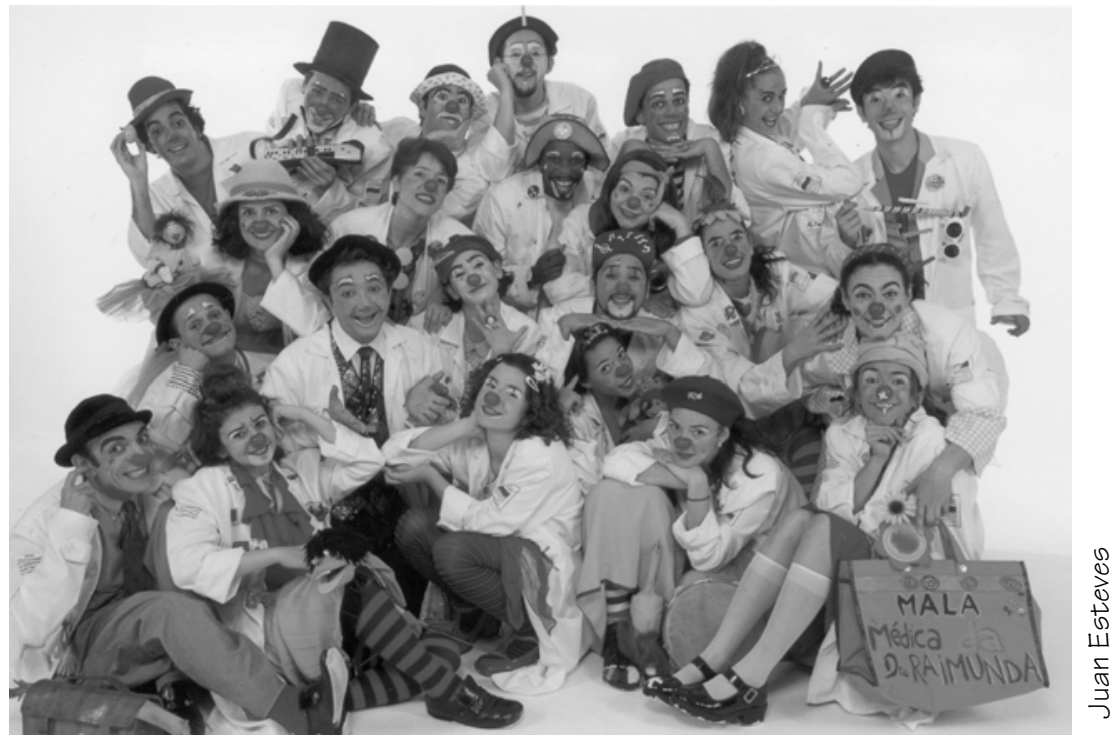

Recebido para publicação em: 31/05//05. Aprovado para publicação em: 07/06/05. 